\title{
Hydrodynamic effects on fast monohulls or catamarans travelling through the critical speed in shallow water
}

\author{
T. P. Gourlay ${ }^{1}$
}

(Received 3 December 2009; revised 15 April 2010)

\begin{abstract}
The speed of linear waves in shallow water approaches a constant value as the wavelength becomes large relative to the water depth. For ships travelling in shallow water, this speed is known as the 'critical speed' and acts as a barrier, similar to the speed of sound for aeroplanes. The possibility of travelling at transcritical and supercritical speeds is discussed for existing monohull and catamaran ships. We explore the predicted linearised flow around a ship as it approaches the critical speed, and the singularities that result. Experimental results show the actual flow patterns that occur at ship speeds close to the critical speed, for monohulls or catamarans, in open water or confined channels.
\end{abstract}

http://anziamj. austms.org.au/ojs/index.php/ANZIAMJ/article/view/2635 gives this article, (C) Austral. Mathematical Soc. 2010. Published April 27, 2010. ISSN 1446-8735. (Print two pages per sheet of paper.) 


\section{Contents}

1 Critical speed in shallow water

C138

2 Basic linearised flow around a ship in shallow water

C142

3 Transcritical flow past a monohull in open water

C143

4 Transcritical flow past a ship in a channel

C148

5 Transcritical flow past a catamaran

C150

6 Conclusions

C151

References

C152

\section{Critical speed in shallow water}

We concentrate on 'displacement' vessels, as opposed to planing vessels. Displacement vessels are moderate to large in size, such that their weight is supported almost entirely by buoyancy forces. Small planing boats, by contrast, may have a large proportion of their weight supported by hydrodynamic lift. The importance of hydrodynamic lift is characterized by the Froude number

$$
F_{L}=\frac{U}{\sqrt{g L_{W L}}} .
$$

For $\mathrm{F}_{\mathrm{L}}<0.4$, hydrodynamic lift is minimal and the vessel is supported almost completely by buoyancy forces [18]. The vessel is then considered to operate in the 'displacement' regime, as assumed in this article.

The phase speed of linear water waves relates to their wavelength through 
B

C

$\mathrm{F}_{\mathrm{h}}$

$\mathrm{F}_{\mathrm{L}}$

g

h

L

$\mathrm{L}_{\mathrm{BP}}$

LOA

LWL

$s_{\max , \text { stern }}$

$S(x)$

$S_{\max }$

$t(x)$

$\mathrm{T}$

U

V

w

$x$

$X$

y

$z$

$\Phi(x, y, t)$ $\phi(x, y)$ $\lambda$
TABLE 1: Nomenclature

ship beam (breadth)

wave speed

Froude number based on water depth

Froude number based on ship waterline length

acceleration due to gravity, $9.81 \mathrm{~m} / \mathrm{s}^{2}$

water depth

ship submerged length

ship length between perpendiculars

ship length overall

ship waterline length

maximum stern sinkage

ship submerged cross-sectional area at station $\mathrm{x}$ ship maximum cross-sectional area

half-thickness of surface-piercing strut or thin aerofoil at station $\mathrm{x}$

ship draft

ship speed

ship submerged volume

channel width

longitudinal coordinate, centred at submerged midships, positive aft

earth-fixed longitudinal coordinate, positive aft transverse coordinate, centred on ship centreline, positive to starboard

vertical coordinate, centred at undisturbed free surface, positive upwards

total velocity potential

disturbance velocity potential

wavelength 
the dispersion relation [20]

$$
c=\sqrt{\frac{g \lambda}{2 \pi} \tanh \frac{2 \pi h}{\lambda}} .
$$

In the limit of long waves in shallow water $(h / \lambda \rightarrow 0)$, linear waves are dispersionless, with the wave speed independent of wavelength, that is

$$
c=\sqrt{g h} .
$$

When a displacement vessel travels in shallow water at close to the speed $\sqrt{\mathrm{gh}}$, the transverse waves it produces are of similar length to the shiplength. At the same time, the shiplength is large compared to the water depth, so that the long wave limit applies, and the waves produced by the ship are nearly dispersionless, with speed $\sqrt{g h}$. A resonance is set up, in which the waves produced by the ship reach infinite amplitude according to first order linear theory.

In practice, no singularities exist, as the wavemaking is limited by dispersion and nonlinearity. Nonetheless, the speed $\sqrt{g h}$ constitutes a very real speed barrier for ships, around which the wavemaking resistance, sinkage and trim all reach a peak. This speed is therefore known as the 'critical speed' for ships.

Most large ships do not have sufficient power to pass through the critical speed into the supercritical region. Table 2 lists some examples of the types of ships that may be able to travel at transcritical and supercritical speeds. The depths shown are the shallowest depths at which each ship can pass safely through the critical speed without grounding. 


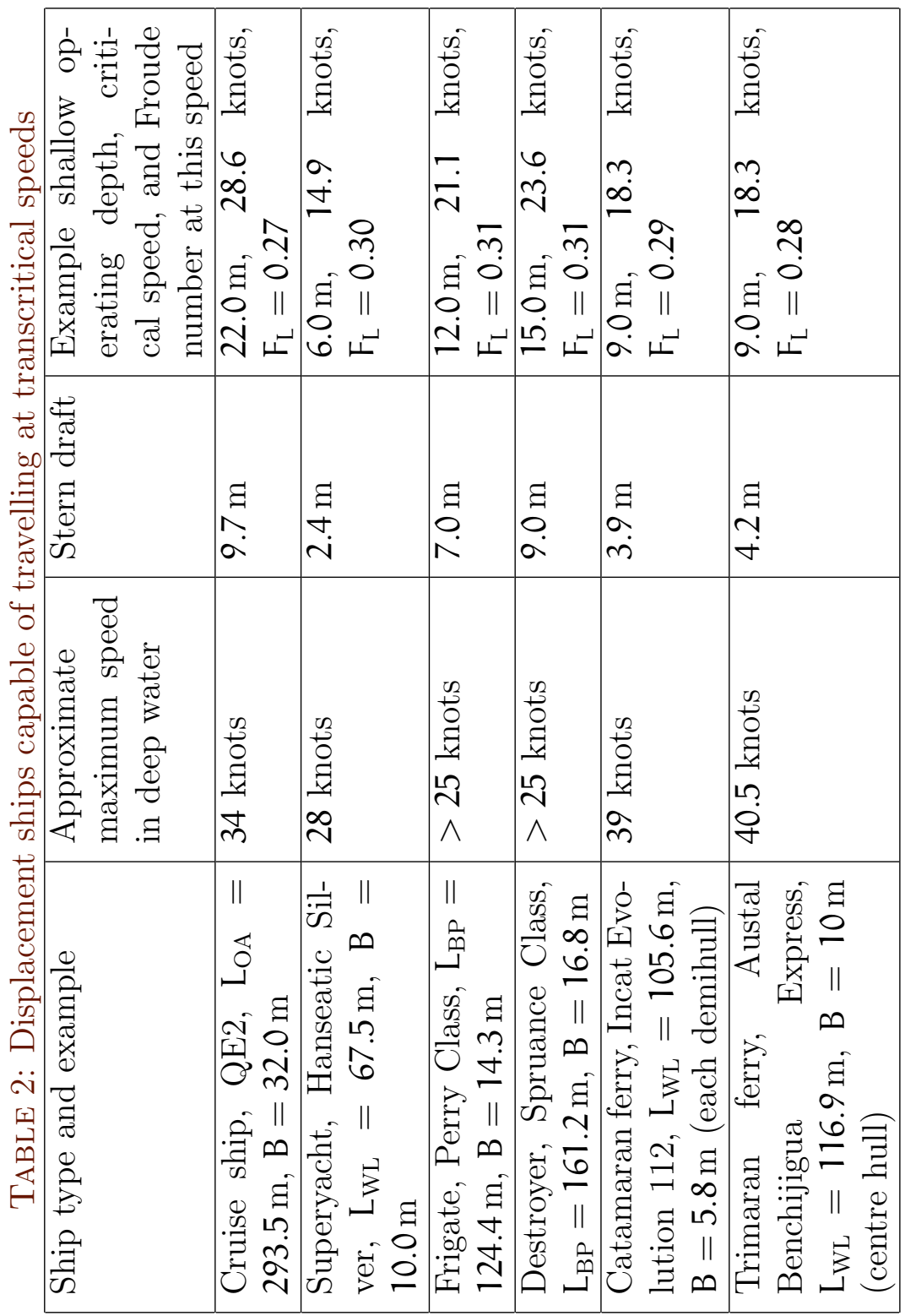




\section{Basic linearised flow around a ship in shallow water}

We use Laplace's equation for irrotational, incompressible flow, plus the dynamic boundary condition on the free surface, and kinematic boundary condition on the hull, free surface and seabed (assuming constant depth). By assuming small free surface elevations, and small water depth relative to the shiplength, the leading order flow satisfies the wave equation [19]

$$
\frac{\partial^{2} \Phi}{\partial t^{2}}=c^{2}\left(\frac{\partial^{2} \Phi}{\partial x^{2}}+\frac{\partial^{2} \Phi}{\partial y^{2}}\right)
$$

Equation (3) gives the wave speed c. This same equation governs twodimensional acoustic waves (with $\mathrm{c}$ the speed of sound), so we expect some similarities between shallow water flow and aerodynamics.

Assuming steady flow past the ship, and switching to ship-fixed coordinates, the disturbance velocity potential satisfies

$$
\left(1-F_{h}^{2}\right) \frac{\partial^{2} \phi}{\partial x^{2}}+\frac{\partial^{2} \phi}{\partial y^{2}}=0
$$

This is the standard slender body, shallow water equation, as derived by Michell [17] for a thin vertical strut of constant cross-section, and later applied to ship hulls by Tuck [21] using matched asymptotics. The same equation is also used for aerodynamic flow past a thin aerofoil, with $F_{h}$ replaced by the Mach number. For the thin, surface piercing strut studied by Michell, or the thin aerofoil, the boundary condition on the body is

$$
\frac{\partial \phi}{\partial y}\left(x, 0_{ \pm}\right)= \pm \mathrm{U} \frac{\mathrm{dt}}{\mathrm{d} x}
$$

Tuck [21] found that the same body boundary condition holds for a slender ship, with $t$ the half-thickness of the hull averaged over the water depth. In 
terms of the ship cross-sectional area, this boundary condition is

$$
\frac{\partial \phi}{\partial y}\left(x, 0_{ \pm}\right)= \pm \frac{\mathrm{u}}{2 \mathrm{~h}} \frac{\mathrm{d} S}{\mathrm{~d} x} .
$$

The matched asymptotics used by Tuck [21] assume that the ship beam and draft, as well as the water depth, are all small compared to the ship's length.

While equation (5) has been shown to give good results for flow past a ship travelling at subcritical or supercritical speeds, it degenerates for a ship travelling at the critical speed $F_{h}=1$; the flow field is undefined in this case. Further terms are needed for a ship travelling in the transcritical speed range.

\section{Transcritical flow past a monohull in open water}

A general equation of motion for steady transcritical flow past a slender monohull in shallow open water $[16,6]$ is

$$
\left(1-F_{h}^{2}\right) \frac{\partial^{2} \phi}{\partial x^{2}}+\frac{\partial^{2} \phi}{\partial y^{2}}+\frac{h^{2}}{3} \frac{\partial^{4} \phi}{\partial x^{4}}-\frac{3}{u} \frac{\partial \phi}{\partial x} \frac{\partial^{2} \phi}{\partial x^{2}}=0 .
$$

subject to the same boundary condition (7). The first two terms in equation (8) constitute the standard slender body, shallow water equation (5). The next term is the dominant effect of dispersion, to leading order in $\mathrm{h} / \mathrm{L}$. The last term is the dominant effect of nonlinearity, to leading order in B/L.

Equation (8) is a two-dimensional extension of the steady one-dimensional Korteweg-deVries equation. In the Korteweg-deVries equation, the nonlinear term acts to steepen waves, while the dispersive term acts to flatten waves. 'Solitary waves' have the correct shape such that the effects of nonlinearity and dispersion are balanced, and the wave continues unchanged in form. This analogy is relevant to a ship travelling in a channel. 
For a ship travelling in open water, equation (8) is yet to be solved in its present form. The nonlinear term precludes a Fourier transformed solution, while the infinite computational domain makes finite difference solutions difficult.

An asymptotic analysis of equation (8) reveals several independent asymptotic limits being applied simultaneously:

1. small $\mathrm{h} / \mathrm{L}$ (shallow water limit);

2. small B/L (slender body limit);

3. large $w / L$ (open water limit);

4. small $1-F_{h}^{2}$ (transcritical limit).

Care must be taken to ensure that each of these limits are allowed to be reached independently, when seeking to determine a global solution.

Let us firstly look at the open water limit $w / L \rightarrow \infty$. When considering flow in a channel, we show that no steady flow exists for a ship travelling at the critical speed, and over a speed range either side of $F_{h}=1$, that shrinks towards the point $F_{h}=1$ as the channel width approaches infinity. Therefore we must firstly question whether steady transcritical flow is actually possible for a monohull travelling precisely at the critical speed $F_{h}=1$, and the answer to this question remains unresolved mathematically or experimentally.

Equation (8) in its present form allows arbitrary hull slenderness and water shallowness, provided both are small compared to the shiplength. However, given the difficulty in solving this equation, we seek to simplify it for different conditions. Mei [16] showed that the dispersive term may be neglected if

$$
\frac{\mathrm{BT}}{\mathrm{h}^{2}}\left(\frac{\mathrm{L}}{\mathrm{h}}\right)^{2} \gg 1,
$$

while the nonlinear term may be neglected if

$$
\frac{\mathrm{BT}}{\mathrm{h}^{2}}\left(\frac{\mathrm{L}}{\mathrm{h}}\right)^{2} \ll 1 .
$$


Table 3 tests this hypothesis for the example ships and water depths given in Table 2.

In all of the situations shown, nonlinearity rather than dispersion should be the dominant effect near the critical speed. Neglecting the dispersive term in equation (8) yields

$$
\left(1-F_{h}^{2}\right) \frac{\partial^{2} \phi}{\partial x^{2}}+\frac{\partial^{2} \phi}{\partial y^{2}}-\frac{3}{u} \frac{\partial \phi}{\partial x} \frac{\partial^{2} \phi}{\partial x^{2}}=0 .
$$

This is a form of the transonic gas equation, which governs transonic flow past a thin aerofoil. Some progress toward solving the problem by local linearization was made by Lea \& Feldman [15].

However, at this point we must be tempted to consider the dispersive version of equation (8), despite its apparent limitations for realistic ship forms. Some reasons for considering this equation are the following.

- Linear, slender body theory, whilst developed for very slender hull forms, has been shown to give accurate flow predictions for much beamier hull forms than its theoretical limitations. Similarly the transcritical linear theory, whilst strictly only correct for extremely slender hulls, will be shown to also give good flow predictions for realistic hull forms. All hull forms that are capable of travelling at transcritical speeds are much more slender than the bulk carriers, for example, for which linear, subcritical, slender body theory is commonly used.

- For a ship in a channel, nonlinear effects are crucial, as they govern the production of solitary waves, which are a strictly nonlinear phenomenon. However, for a ship in open water, no solitary waves are produced.

- One of the principal reasons for studying transcritical flow around a ship in shallow water is to determine the maximum sinkage (downward vertical displacement) of the ship, in order to assess the risk of the ship running aground. This maximum sinkage is seen to occur at speeds 


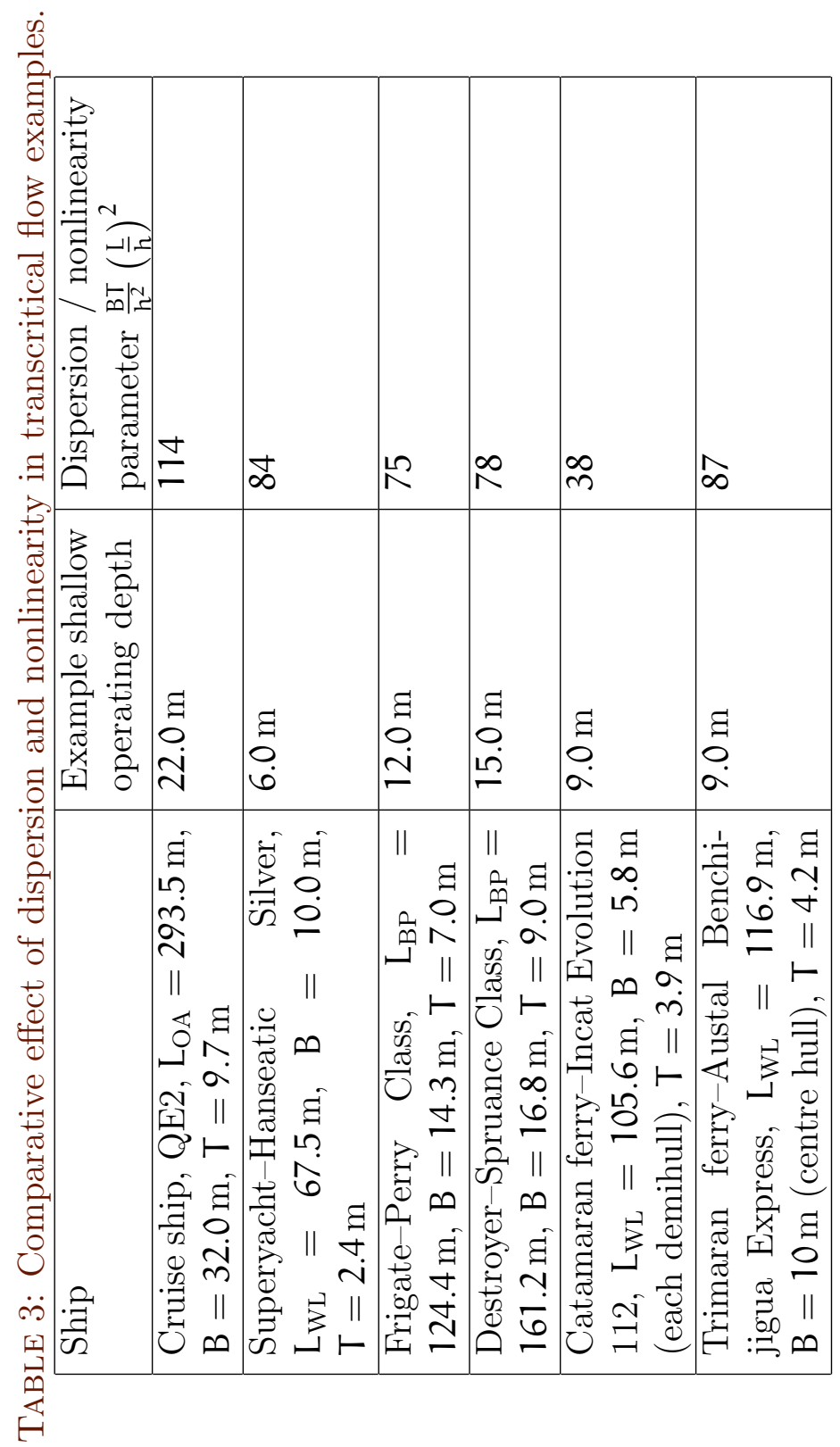


slightly beneath the critical speed, at which nonlinear effects decrease in importance. Dispersion is principally responsible for flattening the waves produced by the ship and limiting the sinkage. This effect was discussed further by Gourlay [6].

The dispersive form of equation (8) is

$$
\left(1-F_{h}^{2}\right) \frac{\partial^{2} \phi}{\partial x^{2}}+\frac{\partial^{2} \phi}{\partial y^{2}}+\frac{h^{2}}{3} \frac{\partial^{4} \phi}{\partial x^{4}}=0 .
$$

subject to the boundary condition (5). This equation can be solved by Fourier transform, using Filon quadrature for the transforms and careful treatment of singularities in the Fourier integral [8]. It was shown that the resulting solution accurately predicted the sinkage and trim of a destroyer-type hull form through the transcritical speed range.

With regard to determining the maximum sinkage, in order to assess grounding risk through the transcritical speed range, it is possible to use dimensional analysis to calculate an approximate solution for general hulls [10]. For most modern high speed, displacement hulls, the maximum stern sinkage is estimated from

$$
\mathrm{s}_{\text {max }, \text { stern }}=1.5 \frac{\mathrm{V}}{\mathrm{Lh}} .
$$

This equation has been used to estimate the shallowest depths (given in Table 2) through which each ship may safely pass through the critical speed without grounding.

For ships in moderate water depth, such that neither the shallow water nor deep water limits are applicable, a finite depth theory may be developed to describe the flow [8]. This theory is fully dispersive, and is also able to predict the maximum sinkage through the transcritical speed range. The results from this theory agree with the transcritical shallow water method (12) in the shallow water limit.

The next goal in open water, transcritical flow analysis is to accurately solve the full nonlinear and dispersive equation (12) in an unbounded domain. 


\section{Transcritical flow past a ship in a channel}

A first glance at the transcritical flow equation (12) yields the conclusion that

$$
\frac{\partial^{2} \phi}{\partial y^{2}} \approx 0 \quad \text { near } \quad F_{h}=1
$$

Therefore the flow disturbance due to the ship is nearly one-dimensional, and is felt even at large transverse distances from the ship. This is the reason for the large wave resistance that accompanies transcritical flow, and prevents most ships from being able to reach transcritical speeds.

Since the disturbance due to the ship decays only very gradually with transverse distance near the critical speed, any lateral restriction to the flow, even at a large distance from the ship, can significantly modify the flow pattern. Ang [1] studied the nonlinear transcritical equation (11) for a ship in a channel, and found that no steady solutions exist in a band of speeds either side of the critical speed. This topic was further explored by Chen [2] who found that as the channel width increases, the size of this unsteady speed range shrinks towards $F_{h}=1$. However even very wide channels will still produce unsteady flow near $F_{h}=1$. Graff et al. [12] found that, for a destroyer-type model in a channel with width 36 times the model beam, no steady flow could be obtained for $1.00 \leqslant F_{h} \leqslant 1.07$.

The reason for the non-existence of steady flow near $F_{h}=1$ was first proposed by Constantine [4]. He found that sufficient water could not pass down the sides of the ship to satisfy continuity, without violating energy considerations. This would cause the water to 'pile up' near the bow of the ship, and then be radiated forwards as unsteady waves.

The form of these radiated waves was studied theoretically and experimentally by Huang et al. [13]. They found that the waves resembled periodic solitary waves (or cnoidal waves) and could be described by a KortewegdeVries type equation. Figure 1 shows a photograph of upstream advancing 


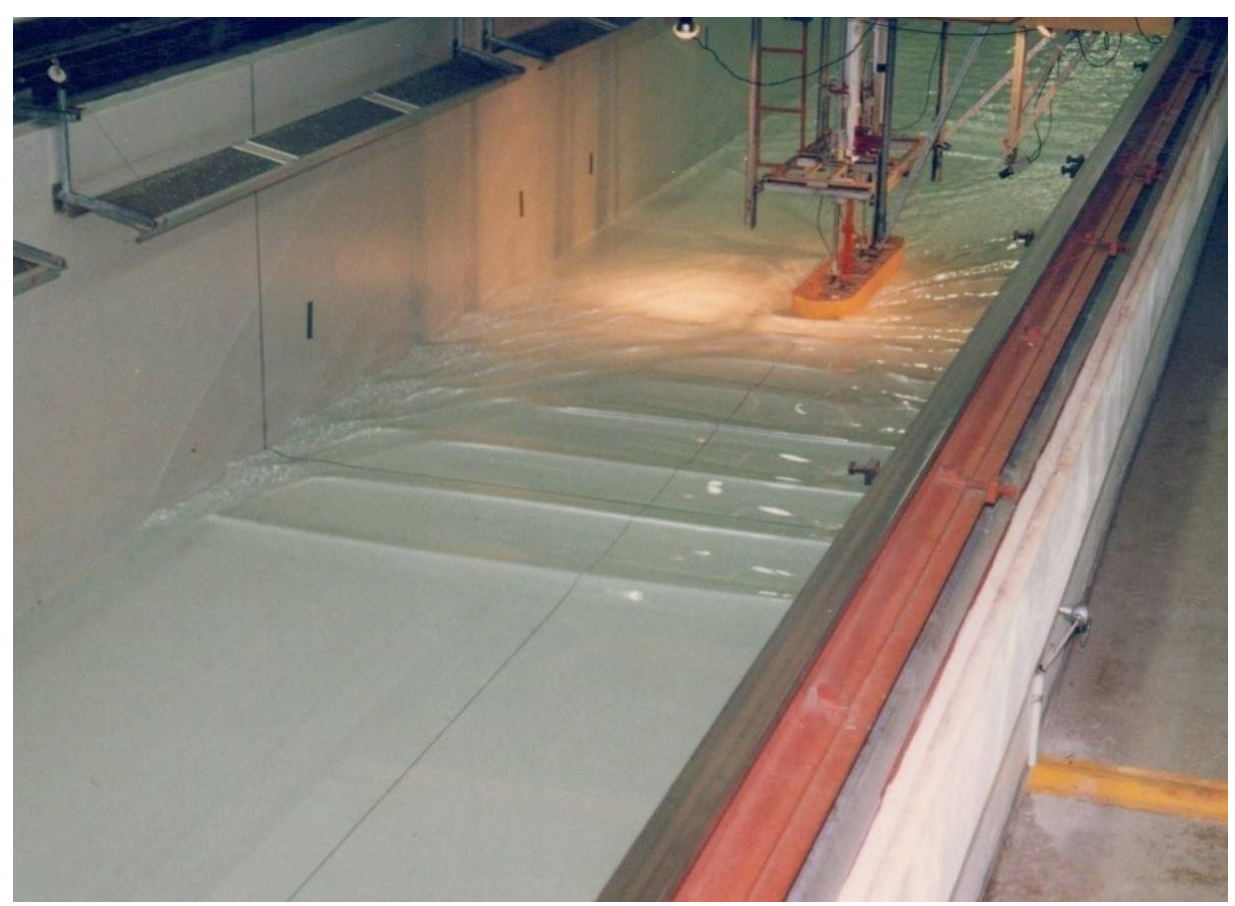

FigURE 1: Upstream advancing solitons produced by a ship in a channel at just above critical speed, during model testing at Australian Maritime College.

solitons produced by a ship model moving at just above the critical speed. The ship is moving towards the camera, and the water ahead of the ship was previously undisturbed. The solitons are moving slightly faster than the ship, and being shed periodically from the ship's bow.

As the speed of the ship is increased further above $F_{h}=1$, the solitons increase in amplitude and then start to break. Slender ships in moderate channel widths will by now have passed into the steady supercritical region. However for narrow channels or non-slender vessels, at $F_{h}=1.2$ the flow will resemble a bore wave travelling ahead of and slightly faster than the ship. 
Behind the breaking bore front, the free surface resembles a raised shelf of water extending from the bore front to the ship. The height and speed of this bore wave can be estimated [7] by combining standard hydraulic theory for one-dimensional bore waves [20] with limiting conditions for steady flow [22]. The wave resistance for ships travelling in this bore-producing speed range is clearly enormous, such that these flows are unlikely for practical ship and channel configurations.

\section{Transcritical flow past a catamaran}

We now consider the case of a catamaran travelling at or near the critical speed in shallow open water. As for a monohull, the catamaran will experience a peak in sinkage, trim and wave resistance at just beneath the critical speed [5]. Linear transcritical theory should be better suited to predicting these peaks than it is for monohulls, due to the very narrow beam of each catamaran demihull (see Table 3). Using linear superposition of the pressure fields produced by each hull [11] yields the linearised combined flow field around the catamaran, and a conclusion that for practical catamaran hull shapes the maximum stern sinkage through the critical speed is estimated using equation (13), as for monohulls.

The linear transcritical theory allows cross-flow to occur beneath each demihull, as is observed in practice. Nevertheless, some lifting effects do occur for catamarans in shallow water, and an improvement to the localized flow prediction may be found by including a Kutta condition at the stern of each demihull [3].

Another localized flow pattern that is peculiar to catamarans is the possibility of wave breaking between the hulls. The superposition of the bow waves due to each demihull causes a locally steepened wave on the centreline between the hulls, which has often been observed to break in deep water [14]. In shallow water, the confined flow between the hulls may cause a bore wave 


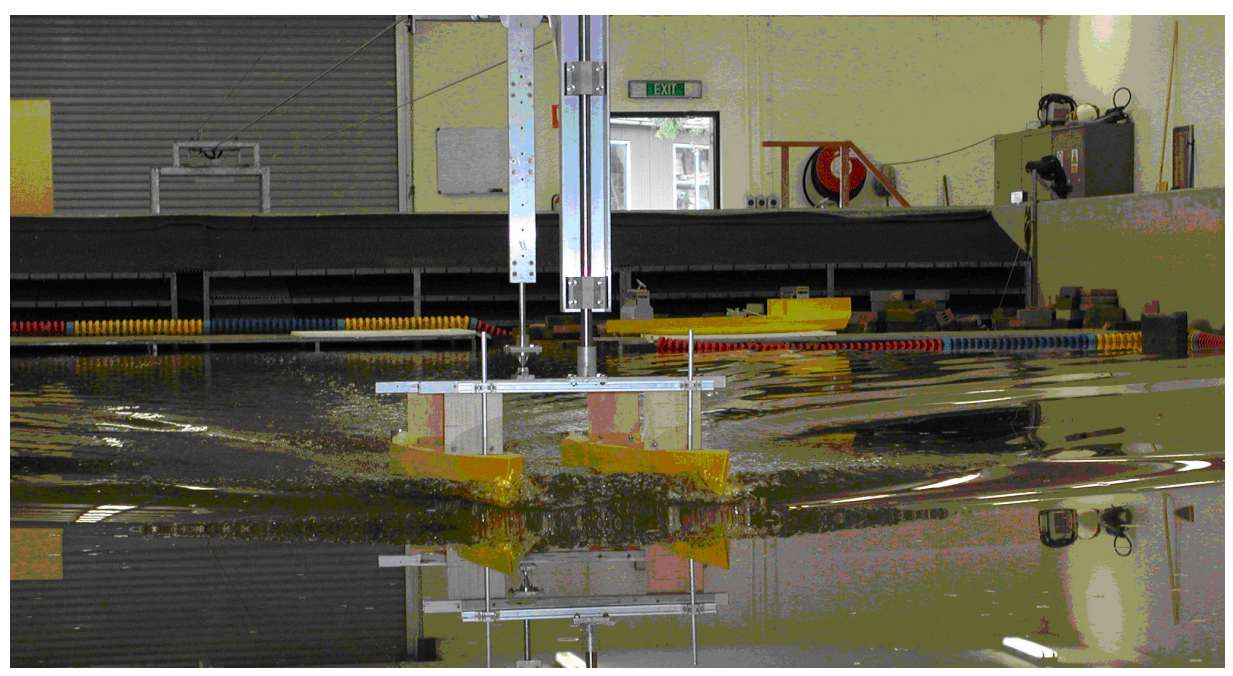

FiguRE 2: Bore wave produced between the demihulls of a catamaran in shallow water. Photograph taken during model testing at AMC.

to be formed, similar to the case of a ship in a channel. Figure 2 shows a photograph of such a bore wave produced in model tests.

Neglecting cross-flow beneath each demihull, the flow between the demihulls is analogous to that of a monohull in a channel. The properties of the bore wave produced between the hulls may then be estimated as described in Section 4. The effect of the cross-flow is to decrease the bore height from that predicted for a monohull in a channel [9].

\section{Conclusions}

The 'critical speed' in shallow water acts as a speed barrier for large vessels, which is just as important, and in many ways analogous, to the speed of sound for aeroplanes. It is accompanied by a peak in resistance, such that only slender, high speed ships may pass through the critical speed and into 
the supercritical speed range. As they do so, a large sinkage and trim are experienced, so that the ship is at high risk of grounding if the static clearance is not sufficiently large. Practical examples of different types of displacement vessels that might pass through the transcritical speed range are given here.

The transcritical flow equation has been analyzed, and solutions discussed for the linearised form of the equation. These have been shown to be in satisfactory agreement with experimental results. Nevertheless, solution of the full nonlinear equation in open water is desirable, and is a topic for further research.

\section{References}

[1] Ang, W. T. 1993 Nonlinear sinkage and trim for a slender ship in shallow water of finite width. Internal report, University of Adelaide. C148

[2] Chen, X. N. 1999 Hydrodynamics of wave-making in shallow water. Ph.D. thesis, University of Stuttgart. C148

[3] Chen, X. N., Sharma, S. D. \& Stuntz, N. 2003 Wave reduction by S-Catamaran at supercritical speeds. Journal of Ship Research 47, No. 1, pp. 1-10. C150

[4] Constantine, T. 1960 On the movement of ships in restricted waterways. Journal of Fluid Mechanics 9, pp. 247-256. doi:10.1017/S0022112060001080 C148

[5] Dand, I. W., Dinham-Peren, T. A. \& King, L. 1999 Hydrodynamic aspects of a fast catamaran operating in shallow water. Proceedings, Hydrodynamics of High Speed Craft, London, November 1999. C150 
[6] Gourlay, T. P. 2000 Mathematical and Computational Techniques for Predicting the Squat of Ships. Ph.D. thesis, University of Adelaide. C143, C147

[7] Gourlay, T. P. 2001 The supercritical bore produced by a high-speed ship in a channel. Journal of Fluid Mechanics 434, pp. 399-409. doi:10.1017/S002211200100372X C150

[8] Gourlay, T. P. \& Tuck, E. O. 2001 The maximum sinkage of a ship. Journal of Ship Research 45, No. 1, pp. 50-58. C147

[9] Gourlay, T. P., Duffy, J. T. \& Forbes, A. 2005 The bore produced between the hulls of a high-speed catamaran in shallow water.

International Journal of Maritime Engineering 147, Part A3, pp. 1-8. C151

[10] Gourlay, T. P. 2006 A simple method for predicting the maximum squat of a high-speed displacement ship. Marine Technology 43, No. 3, pp. 146-151. C147

[11] Gourlay, T. P. 2008 Sinkage and trim of a fast displacement catamaran in shallow water. Journal of Ship Research 52, No. 3, pp. 175-183.

C150

[12] Graff, W., Kracht, A. \& Weinblum, G. 1964 Some extensions of D. W. Taylor's standard series. Trans. SNAME 72, 374-401. C148

[13] Huang, D. B., Sibul, O. J., Webster, W. C., Wehausen, J. V., Wu, D. M. \& Wu, T. Y. 1982 Ships moving in the transcritical speed range. Proceedings, Conference on Behaviour of Ships in Restricted Waters, Varna, Vol. II, pp. 1-10. C148

[14] Insel, M. 1990 An investigation into the resistance components of high speed catamarans. Ph.D. thesis, Department of Ship Science, University of Southampton. C150 
[15] Lea, G. K. \& Feldman, J. P. 1972 Transcritical flow past slender ships. Proceedings, 9th Symposium on Naval Hydrodynamics, ONR, Washington D.C., p1527. C145

[16] Mei, C. C. 1976 Flow around a thin body moving in shallow water. Journal of Fluid Mechanics 77, pp. 737-751. doi:10.1017/S0022112076002863 C143, C144

[17] Michell, J. H. 1898 The wave resistance of a ship. Philosophical Magazine 45, pp. 106-123. C142

[18] Müller-Graf, B. 1995 General resistance aspects of advanced fast marine vehicles. Proceedings, Design of Advanced Fast Marine Vehicles, September, Glasgow. C138

[19] Newman, J. N. 1977 Marine Hydrodynamics, MIT Press. C142

[20] Stoker, J. J. 1957 Water Waves. Interscience. C140, C150

[21] Tuck, E. O. Shallow water flows past slender bodies. Journal of Fluid Mechanics 26, pp. 81-95. doi:10.1017/S0022112066001101 C142, C143

[22] Tuck, E. O. 1974 One-dimensional flows as slender-body problems, with applications to ships moving in channels. Proceedings, Workshop on Slender Body Theory, Ann Arbor. University of Michigan Report NAME 164, pp. 27-35. C150

\section{Author address}

1. T. P. Gourlay, Centre for Marine Science and Technology, Curtin University, Western Australia, Australia. 